\title{
Categorization reduces the effect of context on hedonic preference
}

\author{
Debra A. Zellner and Megan C. Mattingly \\ Montclair State University, Montclair, New Jersey \\ AND \\ SCOTT PARKer \\ American University, Washington, DC
}

\begin{abstract}
When moderately hedonically positive test stimuli are presented following better-liked context stimuli, preferences between the test stimuli are reduced. This reduction in preference, hedonic condensation, occurs in settings that also produce negative hedonic contrast - the phenomenon in which moderately hedonically positive test stimuli seem less positive when they follow better-liked context stimuli. Subjects who were instructed that the context and test stimuli were from different categories exhibited less hedonic condensation. Those categories have smaller hedonic ranges than does the full stimulus set. The increase in preference magnitude with reduction in size of the hedonic range is predicted by Parducci's (1995) range-frequency model.
\end{abstract}

When studying the hedonic evaluation of stimuli, researchers can measure either liking (the hedonic value of a particular item) or preference (the difference in the degree to which two or more things are liked). For example, if we ask someone to rate how much they like either Beethoven or Mozart, we are measuring liking; if we ask which of the two they like better and by how much, we are measuring preference. The study of context effects in hedonics has generally focused on liking, in particular on hedonic contrast as it was conceived by Fechner (1898): "That which gives pleasure gives more pleasure the more it enters into contrast with sources of displeasure or of lesser pleasure; and a corresponding proposition holds for that which gives displeasure" (in Beebe-Center, 1932/1965, p. 232).

The phenomenon that Fechner (1898) predicted, hedonic contrast, does occur (see, e.g., Kenrick \& Gutierres, 1980; Wedell, Parducci, \& Geiselman, 1987). We have demonstrated the occurrence of both negative and positive hedonic contrast with a variety of stimuli. Negative hedonic contrast occurs if moderately hedonically positive test stimuli are rated less positively when they follow better-liked context stimuli than when they are presented alone (see, e.g., Rota \& Zellner, 2007; Zellner, Rohm, Bassetti, \& Parker, 2003). Positive hedonic contrast occurs if moderately hedonically positive test stimuli are rated better when they follow less-well-liked context stimuli than when they are presented alone (see, e.g., Dolese, Zellner, Vasserman, \& Parker, 2005).

Although there are many demonstrations of context effects on liking (hedonic contrast), there is only one of con- text effects on preference magnitude, which is the focus of this article. In the only demonstration of an effect of context stimuli on preference magnitude (Zellner, Allen, Henley, \& Parker, 2006), the degree of preference between two moderately pleasant-tasting test beverages was reduced when they followed very pleasant-tasting context beverages. We called this diminution of preference hedonic condensation.

Hedonic condensation can thus be induced using the same procedures that give rise to negative hedonic contrast. Both occur when a set of moderately hedonically positive stimuli follow context stimuli that are more hedonically positive. This suggests that hedonic contrast (the effect of context on liking ratings) and hedonic condensation (the effect of context on degree of preference) might be related phenomena.

Both hedonic contrast and hedonic condensation can be explained by Parducci's (1968) range-frequency theory. Indeed, Parducci (1995) does think that his theory applies to hedonics. (Some similar ideas also appear in Sarris's [2006] similarity-classification model, but these have not yet been applied to hedonics.) Liking for moderately hedonically positive stimuli will diminish when the stimulus range expands to include better-liked stimuli (Parducci, 1965). The theory also predicts that this same range expansion will decrease subjects' preferences among stimuli of lesser hedonic value. (The importance of these rangeinduced reductions in preference for decision-making processes is addressed in Wedell [1998].) That is, hedonic condensation should occur when subjects view highly hedonically positive context stimuli prior to rating their

D. A. Zellner, zellnerd@mail.montclair.edu 
degree of preference between members of a pair of only moderately hedonically positive test stimuli (Parducci, 1995), as Zellner et al. (2006) found.

If our findings of context effects on contrast and condensation were the product of the hedonic extent of the stimulus range, then causing subjects to categorize the context stimuli and test stimuli into two different smaller hedonic ranges should reduce both hedonic contrast and hedonic condensation.

Rota and Zellner (2007) recently demonstrated such an effect of categorization on hedonic contrast. Hedonic contrast was eliminated when subjects considered the test stimuli and context stimuli to be in different categories. Because flower experts put attractive irises (context stimuli) and less attractive orchids (test stimuli) into different categories, no hedonic contrast was seen in the ratings of the orchids. Because flower novices put both kinds of flowers into the same category (i.e., flowers), however, their ratings did exhibit hedonic contrast.

In other studies, we have demonstrated that instructions to think about the context and test stimuli as being in different categories can attenuate (but not eliminate) hedonic contrast (see, e.g., Dolese et al., 2005; Zellner et al., 2003); thus, thinking of the context and test stimuli as being from different categories of stimuli diminishes hedonic contrast.

To our knowledge, there have been no studies investigating the effect of categorization on hedonic condensation. Parducci (1995), however, believed that a restriction of range like that caused by categorization should reduce or eliminate hedonic condensation. Parducci (1995, p. 156) related the experiences of a man who had moved to an isolated area of Northern Alaska. When he first moved there, he reported being bored after a few minutes of watching caribou. At that point in time, his context of pastimes included more interesting experiences from a life not lived in isolation and thus included a wide range of experiences. After a few years in isolation, however, his range of experiences shrank, and he would watch the caribou for hours, "fascinated by their differences in behavior." Shrinking the range of experiences made watching caribou interesting and, in particular, made the instances of watching them more different from one another.

The present experiment investigated whether categorization affects hedonic condensation in the same manner as it does hedonic contrast, using pairs of pictures of highly hedonically positive "tropical birds" as context stimuli and pictures of less hedonically positive "North American birds" as test stimuli (from Zellner et al., 2003). Until now, the only demonstration of hedonic condensation has been in Zellner et al. (2006), which used beverages of varying sweetness. Since it could be argued that the effect that was seen in that study was a by-product of sweetness-intensity reduction and condensation, rather than hedonic condensation per se, we used a more complex visual stimulus set in the present experiment, which eliminated that possible confound.

In Phase I, we attempted to show hedonic condensation using pictures of birds that were described only as "birds" (a category that has a wide range). Then, in Phase II, we determined whether instructions to think of the context and test stimuli as being from different categories attenuates that hedonic condensation in the same manner as it does hedonic contrast. We did this by having subjects categorize the context birds as "tropical birds" and the test birds as "North American birds," rather than having the subjects just think about them all as "birds," as Phase I subjects did. The effect of categorization would presumably be to produce two smaller ranges (i.e., "North American birds" and "tropical birds," rather than simply "birds"); thus, the range in which the test (North American) birds occurred was restricted to the less hedonically positive region. This should diminish the degree of hedonic condensation among the pictures.

\section{METHOD}

\section{Subjects}

Sixty-four undergraduate students who were drawn from the Montclair State University psychology department's subject pool participated ( 45 female, 19 male; mean age $=20.8$ years). Thirtytwo participated in Phase I, and thirty-two participated in Phase II.

\section{Materials}

Color photographs (ranging in size from $13.5 \times 10.5 \mathrm{~cm}$ to $9 \times$ $8.5 \mathrm{~cm}$ ) of birds were cut out of books and pasted onto $17.8 \times 28 \mathrm{~cm}$ white posterboard. The eight stimulus pictures consisted of two pairs of very colorful, attractive tropical context birds and two pairs of less attractive North American test birds, chosen from the pictures that were used in Zellner et al. (2003). They were selected so that the differences in attractiveness ratings for the pictures within a pair were roughly equal across pairs (using the hedonic ratings from Zellner et al., 2003). Our objective was to create four bird pairs within which attractiveness differed by about the same amount.

\section{Procedure}

The present investigation consisted of two phases. In Phase I, we demonstrated hedonic condensation using pictures of birds. Following the demonstration of hedonic condensation, in Phase II we tried, using different subjects, to reduce or eliminate that condensation by instructing subjects to think of the context and test birds as being in different categories.

Phase I: Hedonic condensation. Thirty-two subjects were randomly assigned to one of two groups: Context or Control $_{\text {I. All sub- }}$ jects were told that they would be rating "pictures of birds." Subjects

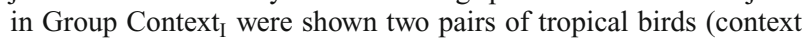
birds), followed by two pairs of North American birds (test birds).

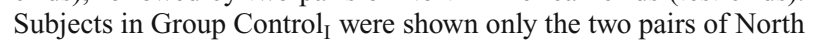
American birds (test birds).

Subjects were tested individually. They were shown a pair of birds until they had finished answering a series of questions about that pair. Subjects in both groups were asked whether they liked one of the birds more than the other in each pair. If they did, they were then asked which one they preferred and how much more they liked it than they liked the other. They indicated their degree of preference using a 10-point scale $(1=$ slightly more, $4=$ somewhat more, $7=$ a lot more, and $10=$ very much more). If a subject had no preference between a pair of birds, the experimenter assigned a rating of 0 for that pair.

Phase II: Categorization effect. Each person in a different set of 32 subjects was randomly assigned to one of two groups: Context or Control ${ }_{\text {II }}$. Subjects in Group Context II saw the same stimuli that subjects in Context $t_{I}$ had; they were shown two pairs of tropical birds (context birds), followed by two pairs of North American birds (test birds), but Phase II subjects were told that the birds were from differ- 
ent categories. These subjects were first told that they would be rating "tropical birds." After rating the two pairs of tropical birds, they were asked whether they would mind rating another set of pictures and were told that this set would be "North American birds." All subjects obliged. Subjects in Group Control ${ }_{I I}$, like those in Control ${ }_{I}$, were shown only the two pairs of North American birds (test birds) but were told that they would be rating "North American birds." Otherwise, the procedure was identical to that of Phase I.

\section{RESULTS}

\section{Phase I: Hedonic Condensation}

For each subject in Context $\mathrm{I}_{\mathrm{I}}$, we calculated the average preference rating for the two pairs of tropical context birds. For each subject in both Context and Control $_{\mathrm{I}}$, we calculated the average preference rating for the two pairs of North American test birds. The group means of these individuals' average preference ratings is in Table 1. As in all subsequent data sets, variances did not differ significantly between the two samples, and both samples' skewness and kurtosis were consistent with sampling from normally distributed populations. The data were thus analyzed using $t$ tests. Context $\mathrm{I}_{\mathrm{I}}$ subjects gave significantly smaller preference ratings for the test birds than

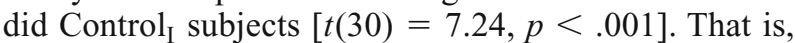
hedonic condensation occurred. Our effect-size indicator, omega squared $\left(\omega^{2}\right)$, measured the proportion of variance that the difference in population means accounted for (estimated $\omega^{2}=.62$ ).

\section{Phase II: Categorization Effect}

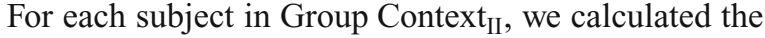
average preference rating for the two pairs of tropical context birds. For each subject in both Groups Context II $_{\text {II }}$ and Control $_{\mathrm{II}}$, we calculated the average preference rating for the two pairs of North American test birds. The group means of these individuals' average preference ratings are in Table 1. There was no significant difference between Context $_{\text {II }}$ and Control II $_{\text {II }}$ subects in their preference ratings for the test birds $\left[t(30)=1.65, p=.11\right.$, estimated $\omega^{2}=$ $.05]$; thus, no significant condensation was seen.

\section{Comparisons Across Phases}

Although it is clear that significant condensation occurred without categorization in Phase I but did not occur with categorization in Phase II (in which instructions led

Table 1

Means and Standard Deviations of Preference Ratings for All Stimuli in Phases I and II

\begin{tabular}{|c|c|c|c|c|}
\hline \multirow[b]{2}{*}{ Group } & \multicolumn{2}{|c|}{$\begin{array}{c}\text { Context Birds } \\
\text { (Tropical) }\end{array}$} & \multicolumn{2}{|c|}{$\begin{array}{l}\text { Test Birds } \\
\text { (North } \\
\text { American) }\end{array}$} \\
\hline & $M$ & $S D$ & $M$ & $S D$ \\
\hline \multicolumn{5}{|l|}{ Phase I } \\
\hline Context $_{\mathrm{I}}$ & 4.3 & 1.5 & 2.0 & 1.6 \\
\hline Control $_{I}$ & - & - & 4.3 & 1.3 \\
\hline \multicolumn{5}{|l|}{ Phase II } \\
\hline Context $_{\text {II }}$ & 3.8 & 1.5 & 3.8 & 2.3 \\
\hline Control $_{\text {II }}$ & - & - & 4.8 & 1.6 \\
\hline
\end{tabular}

to the production of categories with two separate ranges, each narrower than the original range), we do not yet have a direct assay of the degree of attenuation of the condensation that was due to categorization. Furthermore, we must consider the possibility that simply calling pictures of birds "tropical" or "North American" rather than "birds" might itself alter the magnitudes of subjects' preferences among the pictures. We now turn to these issues.

First, we considered the possible effects of changing the labels on the pictures. There was no significant difference between the preference ratings for the context stimuli (tropical birds) by subjects in Groups Context and Context $\left[\mathrm{II}(t 30)=1.37, p=.18\right.$, estimated $\left.\omega^{2}=.03\right]$. Similarly, there was no significant difference between the preference ratings for the test stimuli (North American birds) by subjects in Groups Control ${ }_{\text {I }}$ and Control ${ }_{\text {II }}$ $\left[t(30)=1.18, p=.25\right.$, estimated $\left.\omega^{2}=.01\right]$. Not only were the differences nonsignificant, the proportions of variance that are attributable to these possible effects were negligible. The mere fact of changing the labels on the pictures from "birds" to "North American" or "tropical," therefore, did not itself alter subjects' preference judgments.

The preference ratings for the test (North American) birds by subjects in Groups Context ${ }_{I}$ and Context ${ }_{I I}$ did differ significantly, however $[t(30)=3.20, p<.004$, estimated $\left.\omega^{2}=.25\right]$. The preference ratings were larger for Context ${ }_{\text {II }}$, the subjects who were told that the tropical and North American birds came from different categories; thus, subjects for whom tropical and North American birds were in separate categories exhibited less condensation than did subjects for whom all birds were in the same category. This result was not due simply to the change of categorical designation on the pictures ("birds" vs. "tropical" or "North American"), but rather to the fact that there was categorization in Phase II but not in Phase I.

\section{DISCUSSION}

The results of Phase I demonstrate another instance of hedonic condensation, in this case using visual stimuli instead of chemosensory ones (Zellner et al., 2006). Because the chemosensory stimuli in Zellner et al. (2006) were fruit juices of different concentrations, it is possible that the condensation that was seen in the preference ratings was somehow related to a change in sensory intensity of the flavor (see Riskey, Parducci, \& Beauchamp, 1979). Experiencing intensely sweet context stimuli might have caused subjects in that experiment to perceive the test stimuli as less sweet (and thereby less hedonically positive). This decrease in perceived intensity might also have decreased sensory discriminability, resulting in condensation; however, it is difficult to imagine how any change in sensory intensity might have occurred with the pictures of birds. We therefore believe the present experiment to be the first demonstration of unconfounded hedonic condensation.

In addition, this is the first demonstration that categorization affects preference ratings in much the same way as it does liking ratings. Restricting the range of stimuli by 
dividing the hedonically positive context stimuli and hedonically neutral test stimuli into two different categories reduces or eliminates hedonic contrast (Dolese et al., 2005; Rota \& Zellner, 2007; Zellner et al., 2003). As was shown here, it also eliminates or reduces hedonic condensation. Parducci's (1965) range-frequency theory would explain the effect of categorization on the hedonic condensation that we found in the present experiment as the result of the categorization's producing two smaller hedonic ranges (i.e., tropical birds and North American birds vs. simply birds). The test birds are thus restricted to the less hedonically positive range (the same range that was experienced by control subjects who were presented with only the test stimuli), thereby increasing the degree of preference.

Although both the categorization effect in hedonic contrast that has been found previously and the present categorization effect in hedonic condensation are predicted by Parducci's (1965) range-frequency model, this model has been applied mostly to sensory intensity ratings. Categorization affects contrast in ratings of sensory intensity in much the same way as it affects hedonic contrast (Bevan \& Pritchard, 1963; Brown, 1953; Coren \& Miller, 1974; Stapel \& Koomen, 1997). For example, Brown found in his study of judged weights that contrast was reduced when the heaviest weight (the anchor) was a tray rather than a weight that appeared to be similar to the other judged weights (brass cylinders painted black).

Our experiment evaluated preference judgments, which are essentially judgments of hedonic difference. Previous studies of range effects have focused on discriminability rather than on difference, and those studies found that decreasing the stimulus range increases discrimination (size of squares-Parducci \& Perrett, 1971; Wedell, 2008; loudness-Gravetter \& Lockhead, 1973; Lockhead \& Hinson, 1986; but see Parker, Murphy, \& Schneider, 2002). We know of only one study showing an effect of categorization on condensation that resembles the effect that was demonstrated in ours: a study of loudness discrimination that procedurally separated loud and soft tones at a single frequency. In Experiment 4 of Parker et al., subjects were asked to choose (in a twoalternative, forced-choice procedure) the louder of two tones in the $25-30 \mathrm{~dB}$ range (chosen for each subject to produce $75 \%$ to $90 \%$ baseline accuracy). In one condition, the louder stimulus was replaced by a much louder 92-dB tone on some randomly selected trials. In that condition, discriminative accuracy in those trials that presented the original two tones was markedly reduced from baseline (i.e., condensation occurred). In another condition, all trials included only the two soft stimuli but were preceded by the loud 92-dB "warning" tone, and discriminative accuracy remained at its baseline level; thus, two procedures using the same stimuli, differently arranged, produced condensation in one arrangement but not in the other. When the loud tone was procedurally isolated (a warning tone), condensation did not occur; when the loud tone was included in the discriminations, condensation did occur.

Categorization thus affects condensation in hedonics, and a similar result occurs in loudness. Categorization also affects contrast in hedonics, and a similar result occurs in weight and size judgments. Although loudness, size, and heaviness are processed by well-defined sensory systems, hedonics is not. The fact that categorization affects contrast and condensation in both sensory and hedonic systems suggests that there may be some general mechanism common to both.

Parducci's (1995) range-frequency model does predict these effects in the hedonic and sensory realms. Rangefrequency theory predicts that hedonic and sensory discrimination will be more difficult with stimuli that are part of a large range than with stimuli that are from a small range. In their review article, Wedell, Hicklin, and Smarandescu (2007) suggested that the decreased discriminability in larger ranges results from the division of limited attentional resources over a wide range of stimuli. This explains hedonic condensation as a result of decreased attention. Categorization, by reducing the range, increases the attention that is available for the stimuli in the narrowed range, increasing discriminability of sensory stimuli or degree of preference (magnitude of liking difference) of stimuli that vary in hedonic value.

\section{AUTHOR NOTE}

Portions of this research were presented at the 2006 meeting of the International Society for Psychophysics. Correspondence concerning this article should be addressed to D. A. Zellner, Department of Psychology, Montclair State University, Montclair, NJ 07043 (e-mail: zellnerd@ mail.montclair.edu)

\section{REFERENCES}

Beebe-Center, J. G. (1965). The psychology of pleasantness and unpleasantness. New York: Russell \& Russell. (Original work published 1932)

Bevan, W., \& Pritchard, J. F. (1963). The anchor effect and the problem of relevance in the judgment of shape. Journal of General Psychology, 69, 147-161.

Brown, D. R. (1953). Stimulus-similarity and the anchoring of subjective scales. American Journal of Psychology, 66, 199-214.

Coren, S., \& Miller, J. (1974). Size contrast as a function of figural similarity. Perception \& Psychophysics, 16, 355-357.

Dolese, M., Zellner, D. A., Vasserman, M., \& Parker, S. (2005). Categorization affects hedonic contrast in the visual arts. Bulletin of Psychology \& the Arts, 5, 21-25.

FeCHNeR, G. T. (1898). Vorschule der Aesthetik, II (2nd ed.). Leipzig: Breitkopf \& Härtel.

Gravetter, F., \& LockHead, G. R. (1973). Criterial range as a frame of reference for stimulus judgment. Psychological Review, 80, 203-216.

Kenrick, D. T., \& Gutierres, S. E. (1980). Contrast effects and judgments of physical attractiveness: When beauty becomes a social problem. Journal of Personality \& Social Psychology, 38, 131-140.

LocKheAd, G. R., \& Hinson, J. (1986). Range and sequence effects in judgment. Perception \& Psychophysics, 40, 53-61.

PARDUCCI, A. (1965). Category judgment: A range-frequency model. Psychological Review, 72, 407-418.

Parducci, A. (1968). The relativism of absolute judgments. Scientific American, 219, 84-90.

PARDUCCI, A. (1995). Happiness, pleasure, and judgment: The contextual theory and its applications. Mahwah, NJ: Erlbaum.

ParducCI, A., \& PERRETT, L. F. (1971). Category rating scales: Effects of relative spacing and frequency of stimulus values. Journal of Experimental Psychology, 89, 427-452.

Parker, S., Murphy, D. R., \& Schneider, B. A. (2002). Top-down gain control in the auditory system: Evidence from identification and discrimination experiments. Perception \& Psychophysics, 64, 598-615.

Riskey, D. R., Parducci, A., \& Beauchamp, G. K. (1979). Effects of 
context in judgments of sweetness and pleasantness. Perception \& Psychophysics, 26, 171-176.

Rota, L. M., \& Zellner, D. A. (2007). The categorization effect in hedonic contrast: Experts differ from novices. Psychonomic Bulletin \& Review, 14, 179-183.

SARRIS, V. (2006). Relational psychophysics in humans and animals: A comparative-developmental approach. New York: Psychology Press.

StaPel, D. A., \& KoOMEN, W. (1997). Social categorization and perceptual judgment of size: When perception is social. Journal of Personality \& Social Psychology, 73, 1177-1190.

WEDELL, D. H. (1998). Testing models of trade-off contrast in pairwise choice. Journal of Experimental Psychology: Human Perception \& Performance, 24, 49-65.

WedELL, D. H. (2008). A similarity-based range-frequency model for two-category rating data. Psychonomic Bulletin \& Review, 15, 638-643.

Wedell, D. H., Hicklin, S. K., \& Smarandescu, L. O. (2007). Con- trasting models of assimilation and contrast. In D. A. Stapel \& J. Suls (Eds.), Assimilation and contrast in social psychology (pp. 45-74). New York: Psychology Press.

Wedell, D. H., Parducci, A., \& Geiselman, R. E. (1987). A formal analysis of ratings of physical attractiveness: Successive contrast and simultaneous assimilation. Journal of Experimental Social Psychology, 23, 230-249.

Zellner, D. A., Allen, D., Henley, M., \& Parker, S. (2006). Hedonic contrast and condensation: Good stimuli make mediocre stimuli less good and less different. Psychonomic Bulletin \& Review, 13, 235-239.

Zellner, D. A., Rohm, E. A., Bassetti, T. L., \& Parker, S. (2003). Compared to what? Effects of categorization on hedonic contrast. Psychonomic Bulletin \& Review, 10, 468-473.

(Manuscript received December 31, 2008; revision accepted for publication March 24, 2009.) 